\title{
Clavicle Survival as a Free Bone Graft: A Case Report of Minor Modification Added to Pectoralis Major Flap
}

\author{
Mansoureh Mohamadi ${ }^{1}$, Omid Soltaninia (iD ${ }^{2,{ }^{*}}$ and Fereydoun Pourdanesh ${ }^{3}$ \\ ${ }^{1}$ Department of Oral and Maxillofacial Surgery, Dental School, Babol University of Medical Sciences, Babol, Iran \\ ${ }^{2}$ Department of Oral and Maxillofacial Surgery, Dental School, Hamadan University of Medical Sciences, Hamadan, Iran \\ ${ }^{3}$ Department of Oral and Maxillofacial Surgery, Dental School, Shahid Beheshti University of Medical Sciences, Tehran, Iran \\ "Corresponding author: Department of Oral and Maxillofacial Surgery, Dental School, Hamadan University of Medical Sciences, Shahid Fahmideh st, Hamadan, Iran. Email: \\ omid.soltaninia@umsha.ac.ir
}

Received 2016 July 25; Revised 2020 September 14; Accepted 2020 September 20.

\begin{abstract}
Introduction: Reconstruction of the surgically created defects in the head and neck regions is a crucial step in the patients' treatment plan. Regarding the involved tissues, various flaps and grafts have been introduced in the literature. The pectoralis major myocutaneous flap (PMMF) is one of the most versatile flaps with many variations for providing more advantages. Also, when bone tissue is needed, it can be reconstructed via an osteomyocutaneous flap including rib, sternum, or clavicle.

Case Presentation: In this article, a case of oral squamous cell carcinoma with the extension to facial structures and, then, reconstructed with PMMF was presented, in which a medial half of clavicle bone was resected and employed as a free bone graft.

Conclusions: Sectioning clavicle not only increases the arc of rotation and mobility of the PMMF but also provides a new source of bone graft in the vicinity. Besides, the survival of the graft and integration with the native bone is noteworthy.
\end{abstract}

Keywords: Squamous Cell Carcinoma, Clavicle, Bone Transplantation

\section{Introduction}

Since Ariyan's description in 1979, the pectoralis major myocutaneous flap (PMMF) has been the mainstay of reconstructive techniques for large soft tissue defects in the head and neck areas after ablative cancer surgery (1, 2). Also, its easy access to the flap, reliable vascular supply, technical simplicity, coverage of the exposed vessels by muscle after neck dissection, and the ability to provide bulk for obtaining better cosmetic results made it a popular option among the onco-reconstructive surgeons $(3,4)$. Since the PMMF inception, many variations to increase its benefits for the patients' needs have been proposed. Some of these variations modified the flap to include a bony part and, then, changed it to an osteomyocutaneous flap (5). In this article, a full paddle PMMF was applied to cover a large surgical defect in a case with oral squamous cell carcinoma (SCC) spread to the facial structures. The medial portion of clavicular bone was also removed $(6,7)$ and was, then, employed as a free bone graft to reconstruct the mandibular segmental defect. Accordingly, this method can be considered an innovative choice for bone graft in such cases.

\section{Case Presentation}

A 67-year-old Afghan male patient with a chief complaint of a large ulcer on his face was referred to the Oral and Maxillofacial Department of Taleghani Hospital. The patient stated that there was a painful swelling on his right mandibular region, which made him seeking proper medical care in Kabul, Afghanistan since 5 months ago. Two months later, he underwent segmental resection of the right mandibular body. Also, there were no documents for the pathologic diagnosis of the lesion and previous interventions performed in Afghanistan. Also, habitual and medical histories were clear. Extraoral examination revealed a large lobulated cauliflower-like mass with caseous necrosis, ulceration, and pus formation (Figure $1 \mathrm{~A})$. Tumor size was approximately $9 \times 8 \times 7.5 \mathrm{~cm}$. Moreover, two ipsilateral submandibular lymph nodes were palpated, which were reactive to previous surgical intervention. On intraoral examination, he was edentulous and a white keratotic patch was also seen on his right retromolar region. The scar of previous surgery was also remarkable on his right mandibular ridge. His panoramic radiograph demonstrated a segmental resection of the right 
mandibular body and a poor reconstruction of the defect with a mini plate. According to the lack of a documented pathologic report, the patient was scheduled for an incisional biopsy that established the diagnosis of welldifferentiated, keratinizing SCC. Giving the grading system and due to the size and depth of the lesion, the fourth stage was confirmed for tumor. Besides, a whole workup for metastasis was clear; therefore, he was a candidate for the resection of the tumor and the first-stage reconstruction. Informed consent was taken from the patient based on hospital policy.

\subsection{Surgical Procedure}

On the theatre, after inducing general anesthesia and prepping, a margin of $1.5 \mathrm{~cm}$ to $2 \mathrm{~cm}$ was marked. Concerning the size of the defect, a full paddle PMMF (bearing nipple) was designed for the coverage of the defect. Afterward, the lesion was excised in a full-thickness fashion including skin, muscle, and oral mucosa. All the tumor margins were free according to the frozen section testing. Then, the right selective neck dissection (supraomohyoid) was implemented. In the next step, approximately $1 \mathrm{~cm}$ of the mandibular bone adjacent to the defect was resected and, then, bridged with a new reconstruction plate. Subsequently, after the completion of the flap harvesting procedure, the mid part of the right clavicle was resected to omit the pressure from the bone during the rotation of the full paddle pectoralis major flap. This maneuver also helped to raise the flap more cephalic with minimal tension $(6,7)$. The resected clavicular bone was split and, then, applied as a free bone graft, which was secured to the reconstruction plate by screws (Figure 1B). The donor site was comprehensively undermined primarily and sutured in 3 layers. The flap was rotated tension-free and, then, precisely sutured to the recipient bed in 2 to 3 layers. Eventually, bolster packing was applied for dead space reduction and molding of the flap in place (Figure 1C).

After the surgery, the patient was transferred to the intensive care unit for 1 day and was discharged from the hospital after 7 days. The healing period was uneventful. Also, the final pathologic report confirmed the diagnosis of the incisional biopsy and reported that all the margins were free of tumor. After 4 months, he underwent nipple resection from the flap under local anesthesia.

The clavicle, as a free bone graft, was not only survived, but it has also reached the adjacent margins of the mandibular body (Figure 2). There was no sign or symptom for recurrency or any problem related to the bone graft after a 24-month follow-up. Since there were not any signs and symptoms associated with recurrence or other concomitant problems, we used a panoramic image as the only diagnostic test during the follow-up period.

\section{Discussion}

Following a radical surgery for cancer treatment, the first-stage reconstructive phase is almost necessary all the time. In head and neck regions, there are tremendous options available, which should be used based on the patient's condition (8). Considering that microvascular specialist and armamentarium is not available in all the operating rooms and because of the well-established advantages of the PMMF, this flap still is the most versatile in reconstructive surgery $(9,10)$. For all the authors, who have introduced the special modifications for PMMF, a search was performed to find all the variations of PMMF using neighboring bones. The results of this review are presented in Table 1. In 1986, Lee and Lore (7) proposed the resection of the medial half of clavicle bone to obtain an extra length of PMMF and improve the venous return of the flap by eluding pressure on the clavicle, with minimal functional deformity. In this case, as the margins of the tumor were free and it was a well-differentiated SCC, the patient was not considered a candidate for postoperative chemoradiotherapy; therefore, the simultaneous bone grating was performed for him. Regarding Lore and Lee modification (7), clavicle bone was resected and, then, applied as a bone graft without adding another donor site. So, the segmental defect was grafted to regain the integrity of the mandible. Interestingly, despite the gap between the graft and native bone, the clavicle bone graft has survived and integrated with mandibular margins. Since no bone material or autogenous bone particles were used, the gap has been filled spontaneously. The spontaneous bone formation has been reported in the literature with an unknown exact mechanism (11).

In this method, the application of the clavicle as a free bone graft was performed independent of the PMMF design. So, it did not limit the utilization of any required modification needed for the patient's condition. In osteomyocutaneous modifications of this flap, the participant's bone limited the inherent potency of the flap such as a large paddle or special designs $(16,17)$. Thus, if indicated, this technique can be added to all the other variations of PMMF, which are needed to reconstruct a bony segment concurrently.

The limitations of this procedure are the nearby subclavian vessels, which can be considered the source of mas- 

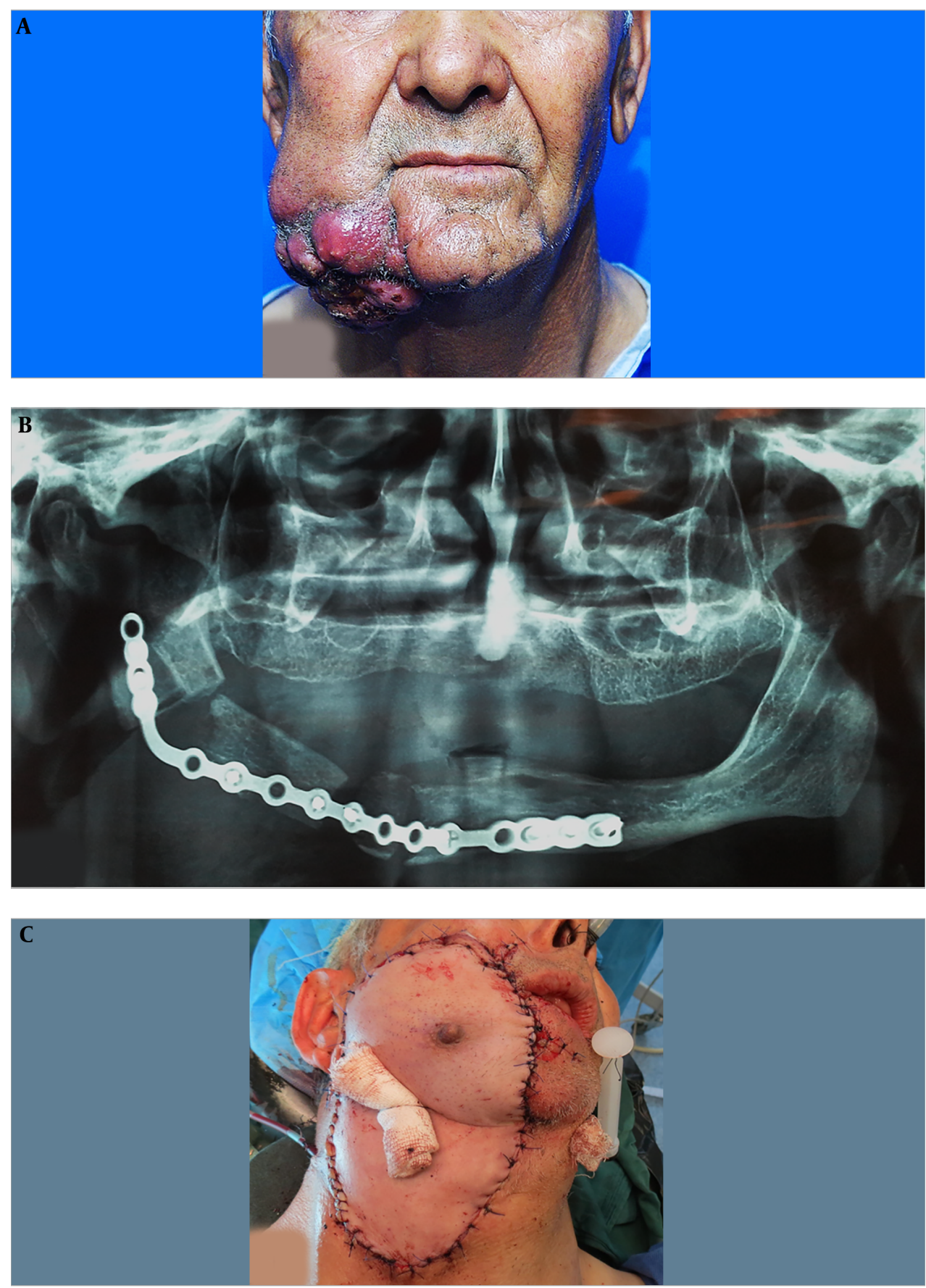

Figure 1. A, Extraoral view of the facial squamous cell carcinoma; B, Post-operative panoramic view shows the reconstructed mandible with plate and clavicle bone graft; C, The last photo of the patient in the operating room, with bolster packs for dead space reduction.

sive bleeding in case of any careless manipulation; however, with a precise subperiosteal approach, this problem can be prevented. After resecting the clavicle, leaving these vessels with no support of the overlying bone may also en- counter the patient to a probable fatal hemorrhage in case of any accidental neck trauma. Accordingly, this problem should also be explained to the patient.

Long term follow-up is required to see how this graft 


\begin{tabular}{|c|c|c|c|}
\hline Author & Modification & Advantages & Disadvantages \\
\hline $\begin{array}{l}\text { Green et al. (12) 1981; Robertson (13) } \\
\text { 1986; Selber and Ghali (14) } 2012\end{array}$ & $\begin{array}{l}\text { Split sternum pectoralis major } \\
\text { osteo-myocutaneous flap for } \\
\text { mandibular reconstruction }\end{array}$ & $\begin{array}{l}\text { High survival rate due to the excellent } \\
\text { vascularity. Does not require special } \\
\text { facilities for microvascular surgery. }\end{array}$ & $\begin{array}{l}\text { Require another surgery to create an } \\
\text { alveolar ridge }\end{array}$ \\
\hline Pearlman et al. (15) 1983 & $\begin{array}{l}\text { Pectoralis major-fifth rib flap: } \\
\text { osteomyocutaneous flap }\end{array}$ & $\begin{array}{l}\text { Can be used in conjunction with a } \\
\text { neck dissection. Do not require the } \\
\text { patient's repositioning. }\end{array}$ & $\begin{array}{l}\text { Chest complication such as the risk of } \\
\text { pneumothorax }\end{array}$ \\
\hline Lee and Lore (7) 1986 & $\begin{array}{l}\text { Resection of the medial half of the } \\
\text { clavicle. }\end{array}$ & $\begin{array}{l}\text { Provide an additional length of this } \\
\text { flap by } 2 \mathrm{~cm} \text { to } 2.5 \mathrm{~cm} \text {. Minimal } \\
\text { functional deformity. }\end{array}$ & $\begin{array}{l}\text { Lack of bony protection afforded by } \\
\text { the clavicle for the subclavian and } \\
\text { axillary vessels. }\end{array}$ \\
\hline Freeman et al. (6) 1989 & $\begin{array}{l}\text { Clavicular division and replacing } \\
\text { technique }\end{array}$ & $\begin{array}{l}\text { Decrease the random portion of the } \\
\text { PMMF. No shoulder dysfunction was } \\
\text { noted. A stable clavicle will cause less } \\
\text { shoulder dysfunction than a } \\
\text { free-floating Clavicle. Gain extra } \\
\text { length may decrease the rate of suture } \\
\text { line separation and orocutaneous } \\
\text { fistulas. Bony protection afforded by } \\
\text { the clavicle for the subclavian and } \\
\text { axillary vessels is maintained. }\end{array}$ & $\begin{array}{l}\text { May compromise vascular pedicle of } \\
\text { the flap. Pressure on flap pedicle after } \\
\text { replacement of clavicle. }\end{array}$ \\
\hline Seikaly et al. $(16,17) 1997$ and 2007 & $\begin{array}{l}\text { Clavipectoral osteomyocutaneous free } \\
\text { flap }\end{array}$ & $\begin{array}{l}\text { Functional and cosmetic donor site } \\
\text { morbidity is minimal even with the } \\
\text { clavicular harvest. The shoulder } \\
\text { morbidity was minimal. Transferred } \\
\text { clavicles demonstrated good } \\
\text { vascularity. }\end{array}$ & $\begin{array}{l}\text { Relatively short pedicle. It should be } \\
\text { used as a second-line flap owing to the } \\
\text { short pedicle. }\end{array}$ \\
\hline $\begin{array}{l}\text { Kerawala et al. (18) 2001; Hoffmann } \\
\text { et al. (19) } 2006\end{array}$ & Subclavicular route & $\begin{array}{l}\text { Increase the arc of rotation of PMMF } \\
\text { without significantly compromising } \\
\text { its vascular supply. This concept } \\
\text { decreases the bulk of the PMMF } \\
\text { pedicle, which is functionally and } \\
\text { cosmetically favorable. }\end{array}$ & $\begin{array}{l}\text { The bulkiness of the flap makes it } \\
\text { difficult for passing deep to the } \\
\text { clavicle. Fracture of the clavicle }\end{array}$ \\
\hline Current technique & $\begin{array}{l}\text { Division of clavicle and applying it as a } \\
\text { free bone graft }\end{array}$ & $\begin{array}{l}\text { The extra length of the flap can be } \\
\text { obtained. Flap manipulation and } \\
\text { application are independent of the } \\
\text { clavicle bone. A bone graft source } \\
\text { without another donor site. Omitting } \\
\text { pressure from overlying bone to the } \\
\text { flap pedicle. }\end{array}$ & $\begin{array}{l}\text { Lack of bony protection afforded by } \\
\text { the clavicle for the subclavian and } \\
\text { axillary vessels. Regional deformity. }\end{array}$ \\
\hline
\end{tabular}

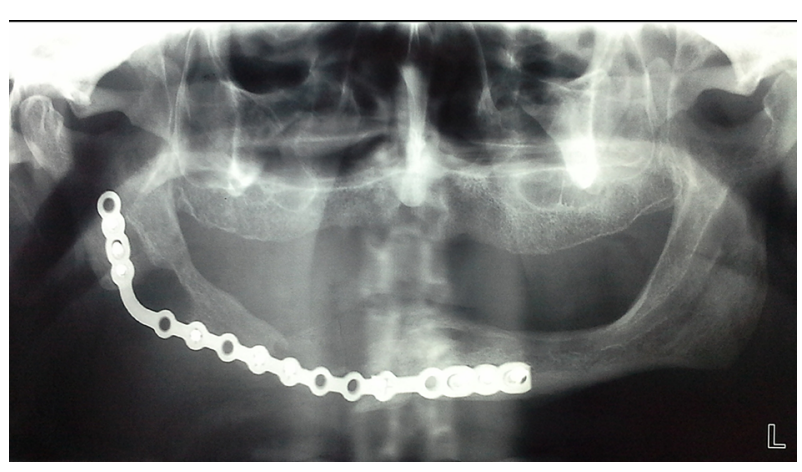

Figure 2. Panoramic view of the patient after 6 months; the clavicle bone has reached the mandibular body margins and underwent some resorption.

continues to exist. Implant rehabilitation also seems to be questionable in such a graft by considering its cortical nature and morphology.

\subsection{Conclusions}

The first-stage reconstruction of ablative surgery is very important for the patient's future rehabilitation and life quality. The reconstructive surgeon should be aware of all the possibilities to increase the benefit to her/his patients. Anyway, the application, advantages, and disadvantages of this method should be evaluated in large case series and clinical trials to consider it a conventional surgical approach.

\section{Footnotes}

Authors' Contribution: Administrative, technical, and material support: FP. Study supervision: FP. Study concept and design: OS and MM. Acquisition of data: OS and MM. Drafting of the manuscript: OS and MM.

Conflict of Interests: There is no conflict of interest. 
Funding/Support: There is no funding support.

Informed Consent: Written and signed informed consent was obtained from patient.

\section{References}

1. McLean JN, Carlson GW, Losken A. The pectoralis major myocutaneous flap revisited: a reliable technique for head and neck reconstruction. Ann Plast Surg. 2010;64(5):570-3. doi: 10.1097/SAP.ob013e3181c51f4a. [PubMed: 20354429].

2. Milenovic A, Virag M, Uglesic V, Aljinovic-Ratkovic N. The pectoralis major flap in head and neck reconstruction: first 500 patients.J Craniomaxillofac Surg. 2006;34(6):340-3. doi: 10.1016/j.jcms.2006.04.001. [PubMed: 16860565].

3. Phillips JG, Postlethwaite K, Peckitt N. The pectoralis major muscle flap without skin in intra-oral reconstruction. Br J Oral Maxillofac Surg. 1988;26(6):479-85. doi: 10.1016/0266-4356(88)90069-1. [PubMed: 3203089].

4. Ahmad QG, Navadgi S, Agarwal R, Kanhere H, Shetty KP, Prasad R. Bipaddle pectoralis major myocutaneous flap in reconstructing full thickness defects of cheek: a review of 47 cases. J Plast Reconstr Aesthet Surg. 2006;59(2):166-73. doi:10.1016/j.bjps.2005.07.008. [PubMed: 16703862].

5. Ord RA, Avery BS. Side-by-side double paddle pectoralis major flap for cheek defects. Br J Oral Maxillofac Surg. 1989;27(3):177-85. doi: 10.1016/0266-4356(89)90141-1. [PubMed: 2742804].

6. Freeman MS, Thomas JR, Zipper JA. Clavicular division technique. A new approach for lengthening the pectoralis flap. Arch Otolaryngol Head Neck Surg. 1989;115(2):224-7. doi: 10.1001/archotol.1989.01860260098022. [PubMed: 2914095].

7. Lee KY, Lore JJ. Two modifications of pectoralis major myocutaneous flap (PMMF). Laryngoscope. 1986;96(4):363-7. doi: 10.1288/00005537198604000-00005. [PubMed:3515080].

8. Wong RJ, Shah JP. The role of the head and neck surgeon in contemporary multidisciplinary treatment programs for advanced head and neck cancer. Curr Opin Otolaryngol Head Neck Surg. 2010;18(2):79-82. doi: 10.1097/MOO.0b013e32833782fo. [PubMed: 20168233].
9. Baek SM, Lawson W, Biller HF. An analysis of 133 pectoralis major myocutaneous flaps. Plast Reconstr Surg. 1982;69(3):460-9. doi: 10.1097/00006534-198203000-00010. [PubMed: 7063569].

10. Carlson ER. Pectoralis major myocutaneous flap. Oral Maxillofac Surg Clin North Am. 2003;15(4):565-75. doi:10.1016/s1042-3699(03)00060-8.

11. Pourdanesh F, Mohamadi M, Khojasteh A, Mashhadiabbas F, Yaghmaei M. Exfoliation and simultaneous formation of condylar process following chronic osteomyelitis of the mandible. J Craniofac Surg. 2012;23(4):e319-22. doi: 10.1097/SCS.0b013e31825433f1. [PubMed: 22801167].

12. Green MF, Gibson JR, Bryson JR, Thomson E. A one-stage correction of mandibular defects using a split sternum pectoralis major osteo-musculocutaneous transfer. Br J Plast Surg. 1981;34(1):11-6. doi: 10.1016/0007-1226(81)90087-4. [PubMed: 7459516].

13. Robertson GA. The role of sternum in osteomyocutaneous reconstruction of major mandibular defects. Am J Surg. 1986;152(4):367-70. doi: 10.1016/0002-9610(86)90306-5. [PubMed: 3766865].

14. Selber JC, Ghali S. Pectoralis major flap with sternum: achieving vascularized osseous reconstruction of the mandible without a free flap. Plast Reconstr Surg. 2012;129(2):389-91. doi: 10.1097/PRS.ob013e31823afido. [PubMed: 22286481].

15. Pearlman NW, Albin RE, O'Donnell RS. Mandibular reconstruction in irradiated patients utilizing myosseous-cutaneous flaps. Am Surg. 1983;146(4):474-7. doi: 10.1016/0002-9610(83)90234-9. [PubMed: 6625091].

16. Seikaly $\mathrm{H}$, Calhoun $\mathrm{K}$, Rassekh $\mathrm{CH}$, Slaughter D. The clavipectoral osteomyocutaneous free flap. Otolaryngol Head Neck Surg. 1997;117(5):547-54. doi: 10.1016/s0194-5998(97)70029-9. [PubMed: 9374182].

17. Seikaly H, Moshaver A, Chau J, Harris JR, Calhoun KH. Clavipectoral osteomyocutaneous free flap in oromandibular reconstruction. J Otolaryngol. 2007;36(3):186-90. [PubMed: 17711775].

18. Kerawala CJ, Sun J, Zhang ZY, Guoyu Z. The pectoralis major myocutaneous flap: Is the subclavicular route safe? Head Neck. 2001;23(10):879-84. doi: 10.1002/hed.1127. [PubMed: 11592235].

19. Hoffmann TK, Ballo H, Hauser U, Bier H. [The subclavicular route for the pectoralis major myocutaneous flap]. HNO. 2006;54(7):523-7. German. doi: 10.1007/s00106-005-1344-9. [PubMed: 16220280]. 